\title{
O Papel do Direito Criminal no Cumprimento dos Direitos Ambientais ${ }^{1}$
}

\author{
Steven Goode
}

\section{Introdução}

É fácil tanto exagerar como também subestimar a importância do direito criminal no cumprimento de leis ambientais nos Estados Unidos. Se examinarmos meramente a quantidade e gravidade de delitos criminais ao meio-ambiente ${ }^{2}$ ou, ainda, a vasta doutrina sobre o tema, teremos uma vasta visão do papel do direito criminal. Se, por outro lado, analisarmos apenas a quantidade de processos e sentenças impostas àqueles condenados en virtude de direitos criminais ambientais ${ }^{3}$ - no que toca particularmente ao universo de atividades reguladas e ao número processos por outros delitos -, concluir-se-ia por um papel relativamente insignificante do direito ambiental.

Neste artigo, tentarei colocar em perspectiva apropriada o papel exercido pelo direito criminal no cumprimento de padrões ambientais. A existência de sançōes criminais, associadas ao cumprimento de leis ambientais, consiste em uma importante arma. Em verdade, é apenas uma das muitas armas disponíveis. Várias espécies de técnicas não-criminais e sanções são utilizadas, normalmente com freqüência muito mator. ${ }^{4} \mathrm{~A}$ ameaça de sançóes criminais, em especial aquela que o indivíduo poder ser preso se violar padróes ambientais gera, ainda que indeterminada, uma parcela de intimidação. Para a maioria dos homens de negócio, a perda de liberdade, diferente o pagamento de uma multa, não poder ser vista apenas como um custo adicional do negócio. ${ }^{5}$

\footnotetext{
1 Texto originalmente escrito em inglês e traduzido para o português por Felipe Francisco Balvé Alice e Ana Gerdau de Borja, da Faculdade de Direito da Universidade Federal do Rio Grande do Sul.

- Fullbright \& Jaworski Professor of Law and Distinguished Teaching Professor na Faculdade de Direito da University of Texas.

2 Veja Parte II, infra.

3 Veja infra-notas $37-42$, e texto em anexo.

${ }^{4}$ Veja infra-notas 43-52, e texto em anexo.

5 Veja Stephen Longoria, The Criminal Prosecution of Environmental Offenders: No Longer a Cost of Doing Business, 60. TEXAS BAR. J. 1118 (1997).
} 
Sanções criminais também têm importante papel. ${ }^{6}$ Elas permitem que a sociedade aponte como "escândalos morais" as EGREGIOUS/egrégias violaçōes ambientais, exercendo duas funções. De qualquer forma, a habilidade de punir criminalmente os infratores atua em ASSUAGE o escândalo moral da sociedade em relação ao infrator. No geral, a criminalização de infrações ambientais apresenta uma função educativa. Quando são impostas sançōes criminais àqueles que infringem padrōes ambientais, a sociedade demonstra que tais delitos se distinguem, qualitativamente, das quebras do contrato - as quais são punidas por açōes privadas de perdas e danos. A criminalização expressa a visão da sociedade daquelas condutas como imorais. Nas palavras de um autor, as leis ambientais "estabelecem as normas gerais fundamentais para o comportamento responsável na sociedade e impóem condições de obrigação moral análogas às de proteção da liberdade de expressão, religiosa, e vedação à discriminação racial e sexual"? đ̇ medida que as geraçóes futuras crescem com isso, como parte do tecido de seu contrato social, terão inculcados os valores ambientais expressos em sua legislação ambiental, assim como as geraçóes anteriores cresceram também com a idéia de que liberdade de expressão, religião e a de vedação à discriminação racial e sexual, sendo qualitativamente diferentes de obrigações contratuais.

Inextricavelmente associadas às expressivas funçóes exercidas pelo direito criminal nesta área, estão os importantes questionamentos relacionados ao modo com que as leis criminais ambientais deveriam ser interpretadas e cumpridas. Dada a maneira pela qual os tribunais vêm interpretando a (EXIGÊNCIA) mens rea da maioria das leis ambientais, há o perigo de que a sanção criminal seja utilizada com arbitrariedade ou liberalidade. Se isso ocorrer, o suporte para a criminalização da conduta ambiental será minado.

\section{Panorama dos Delitos criminais ambientais}

Antes de 1970, o direito criminal não atuou quanto (às preocupaçóes de) à proteção ao meio-ambiente. O Refuse Act de $1899^{8}$ estabeleceu a sanção federal criminal única ${ }^{9}$ a misdemeanor - e nunca foi amplamente utilizada. ${ }^{10} \mathrm{Hoje}$, em contraste, não apenas uma

\footnotetext{
${ }^{B}$ Veja Susan Hedman, Expressive Functions of Criminal Sanctions in Environmental Law 59 Geo. WASH. L. REV. 889 (1991).

7 Christopher H. Schroeder, Cool Analysis Versus Moral Outrage in the Development of Federal Environmental Criminal Law, 35 WILLIAM AND MARY L.REV. 251, 257 (1993).

${ }^{8} 33$ U.S.C. $\$ 407$.

${ }^{9}$ Estados entram, às vezes, com ações civis públicas. Veja 1 Christopher Harris, RAYMond $C$, Marshall, and Patrick O. Cavanaugh, Environimental Crimes 1-3 (1992) (daqui em diante Harris, ENVIRONMENTAL CRIMES).

to Veja Kathleen F. Brickey, Environmental Crime at the Crossroads: The Intersection of Environmental and Criminal Law Theory, 71 Tulane L. Rev. 487, 493 N.23 (1996).
} 
ampla variedade de leis ambientais autoriza sanções criminais, como também as penalidades impostas podem ser bastante severas. ${ }^{1 !}$

As Clear Air Amendments de 1970 USHERED na era dos crimes ambientais. ${ }^{12}$ Em uma década, sanções ambientais foram incorporadas em esquemas regulatórios criados pelo Clear Water Act, ${ }^{13}$ Federal Insecticide, Fungicide, Rodenticide Act, ${ }^{44}$ Safe Water Drinking Act, ${ }^{15}$ Toxic Substances Control Act, ${ }^{16}$ Resource Conservation and Recovery Act, ${ }^{17} \mathrm{e}$ Comprehensive Environmental Response, Compensation, and Liability Act, ${ }^{18}$ para mencionar alguns. ${ }^{19}$ Nos anos seguintes, o Congresso adicionou novos dispositivos criminais aos já existentes, aumentando a severidade de muitos crimes já regulamentados.

As Solid Waste Disposal Act Amendments de 1980 ilustram tal tendência. Essa regulamentação criou o primeiro crime de ameaça ambiental do Resource Conservation and Recovery Act (RCRA) e elevou a status de crime os já existentes mesdemeanors. ${ }^{20} \mathrm{Em}$ 4 anos, o Congresso fortaleceu o crime de ameaça do RCRA, ${ }^{21}$ e no final da década, adicionou delitos similares aos regimes regulatórios criados pelo Clean Water Act ${ }^{22}$ eo Clean Air Act. ${ }^{23}$

Uma discussão abrangente de todos os crimes ambientais vai além do objetivo deste paper. O Clean Air Act, Clean Water Act, RCRA e o Comprehensive Environmental Response, Compensation, and Liability Act (CERCLA) promovem a maioria dos processos criminais ambientais. O Clean Air Act, por exemplo, criminaliza aqueles que conscientemente violam requerimentos legais ou regulatórios. ${ }^{24} \mathrm{~A}$ pessoa pode ser física ou jurídica. Um indivíduo que infringe o Clean Air Act pode ser multado em U\$ 250.000 por dia por violação e preso por até 5 anos; a pessoa jurídica, por sua vez, pode receber a multa de U\$ 500.000 por

\footnotetext{
"Uma obra inteira é destinada ao assunto de delitos criminais ambientais. Veja Harrts, Environmental. Crimes, supra-nota 8.

12 Veja 42 U.S.C. $\$ 7413$ (c) (1).

${ }^{13} 33$ U.S.C. $\$ 1319$ (c).

147 U.S.C. $\$ 136 \mathrm{j}$.

1542 U.S.C. \$300h-2, 300i-1.

${ }_{18} 15$ U.S.C. $\S \S 2614-15$.

1742 U.S.C. $\$ 6928$ (d), (e).

is 42 U.S.C. $\$ 9603$ (b), (d).

${ }^{19}$ Entre outras leis criminais com provisões de cumprimento criminal são Bald and Golden Eagle Protection Act, 16 U.S.C. \$ 668; Emergency Planning and Community Right lo Know Act, 42 U.S.C. $\$ 11045$ (b) (4), (d) (2); Endangered Species Act, 16 U.S.C. \$§ 1538, 1540; Hazardous Materials Transportation Act, 49 U.S.C. $\S 5124$; Marine Protection, Research and Sanctuaries Act, 33 U.S.C. $\S \S 1411,1415$; Migratory Bird Act, 16 U.S.C. $\$ 707$; e Outer Continental Shelf Lands Act, 43 U.S.C. $\$ 1350$.

${ }^{20}$ Solid Waste Disposal Amendments de 1980, Pub. L. No. 96-482, § 13, 94 Stat. 2334, 2339-42.

21 Hazardous and Solid Waste Amendments de 1984, Pub. L. No. 98-616, 98 Stat, 3256-57.

22 Water Quality Act de 1987, Pub. L. No. 100 4, sec. 312, § 309 (c) (5), 104 Stat. 2399, $2676-7$.

${ }^{23}$ Clear Air Act Amendments de 1990, Pub. L. No. 101-549, sec. 701, §113 (c) (5), 104 Stat. 2399 , 2676-77.

${ }^{24}$ Clean Air Act, 42 U.S.C. $\S 7413$ (c) (1).
} 
dia por violaçăo. ${ }^{25}$ O Clean Water Act contém provisóes similares, assim como o RCRA, embora em uma forma mais complicada. ${ }^{26}$

Os crimes de ameaça com culpa consciente, contidos no Clean Air Act, Clean Water Act e RCRA, também são similares. No Clean Air Act, um indivíduo que conscientemente faz emissões de ar poluente perigoso ou de qualquer "substância extremamente perigosa", que póe outra pessoa em "iminente perigo de morte e lesões corporais sérias", fica sujeito a multas de até 250.000 por dia e à prisăo de até 15 anos. ${ }^{27}$ Uma empresa pode ser multada de até $U \$ 1.000 .000$ por dia. ${ }^{28}$ Menores penalidades podem ser impostas aos riscos oriundos de comportamento negligente. ${ }^{29}$ Mais uma vez, provisóes similares aplicam-se no tocante ao Clean Water Act e RCRA. ${ }^{30}$

Além dos crimes criados como parte expressa do regime regulatório do meio-ambiente, muitas outras leis gerais federais podem ser usadas para processar os SCOFFLAWS (zombadores do direito). Muitos dos arranjos ambientais podem submeter o infrator não apenas a sançóes criminais das leis vigentes, ${ }^{31}$ mas a outra provisão geral que faz da submissão de informação falsa ao governo federal crime. ${ }^{32}$ A lei (STATUTE OU STATUE) da fraude de envio pode ser também invocada contra os violadores do meio-ambiente. A utilizaçäo do sistema postal para cometer trapaças ou obter dinheiro ou propriedade através de representações falsas consiste em crime de também possível abrangência a criminosos em âmbito de meioambiente. ${ }^{33}$ Ademais, se uma ou mais pessoas acordam em cometer crime ambiental, serão acusadas de conspiração, além de outros crimes substantivos ambientais que realmente cometam. ${ }^{34}$

Essa ampla variedade de mecanismos de cumprimento da legislação - dos quais quase todos não existiam antes de 1970 - tem sido fortificada por outros dois desenvolvimentos. Primeiro, o advento das Federal Sentencing Guidelines aumentou substancialmente o risco de que alguém, condenado por um crime ambiental, tenha de passar um período na prisão. ${ }^{35}$ Em segundo lugar, em 1990 o Congresso atuou de modo a aumentar as capacidades de cumprimento da Agência

${ }_{25} 18$ U.S.C. $\S 3571$. As penalidades podem ser dobradas, caso haja delitos subseqüentes. 42 U.S.C. $\$ 7413$ (c) (1).

${ }^{26}$ Veja, de modo geral, Harris, Environmental Crimes, supra nota 8.

2742 U.S.C. $\$ 7413$ (c) (5) (A); 18 U.S.C. $\$ 3571$. As penalidades podem ser dobradas, caso haja delitos subseqüentes. 42 U.S.C. $\$ 7413$ (C) (5) (A).

${ }_{28}^{28} 42$ U.S.C. $\$ 7413$ (c) (5) (A). As penalidades podem ser dobradas, caso haja delitos subseqüentes. $t d$. 2942 U.S.C. $\$ 7413$ (C) (4).

${ }^{30}$ Clear Water Act, 33 U.S.C. $\$ 1319$ (c) (3); Resource Conservation and Recovery Act, 42 U.S.C. $\S 6928$ (f).

${ }_{31}$ Clean Water Act, 33 U.S.C. $\$ 1319$ (c) (4); Clean Air Act, 42 U.S.C. $\$ 7413$ (c) (2) (A); Resource Conservation and Recovery Act, 42 U.S.C. $\$ 6928$ (d) (2); e Comprehensive Environmental Response, Compensation, and Liability Act, 42 U.S.C. $\$ 9603$ (b).

3218 U.S.C. \$ 1001 .

3318 U.S.C. § 1341.

3418 U.S.C. $\$ 371$.

${ }^{35}$ Veja Charles P. Bubany, Criminal Enforcement of Environmental Statutes $\$ \S 12.26-12.29$, in

Frank F. Skillern, Environimental. Protection Deskbook (2a ed. 1995). 
de Proteção Ambiental (APA). O Pollution Prosecution Act de 1990 autorizon a quadruplicação no número de investigadores criminais da APA por más de 5 anos. ${ }^{36}$ Conseqüentemente, o número de investigadores criminais empregados pela APA cresceu de 47 no ano fiscal de 1989 para 151 no de $1996 .{ }^{32}$

Tal proliferaçăo de provisóes criminais aumentou a estrutura de penalidades, e melhorou a capacidade de cumprimento, o que reflete claramente a incisivo censo comum (PÚBLICO) de que infratores ambientais sérios devem ser agressivamente processados e severamente punidos. Uma apreciação dos números explicita o que exatamente ocorreu.

No ano fiscal de 1990, a APA submeteu à apreciaçäo do Departamento de Justiça (que é a agência executiva responsável por processos envolvendo casos criminais federais) 65 casos, acusando 100 réus. ${ }^{36} \mathrm{Na}$ época, essas cifras eram recordes altos. No ano fiscal de 1991, 82 réus foram condenados; 28 receberam. penas de prisäo, totalizando 8,3 anos. ${ }^{39}$ Já no ano fiscal de 1994 , o número de encaminhamentos da APA ao Depto. de Justiça cresceu para $220.40 \mathrm{O}$ número de réus acusados cresceu para 250 e as sentenças de prisão cumuladas atingiam 99,0 anos. ${ }^{41}$ Os números decresceram um pouco no ano fiscal de 1996, o último ano em que esses levantamentos estão disponíveis: 262 requerimentos/ ENCAMINHAMENTOS, com 221 réus acusados e penas cumulativas de prisão em 93,0 anos. ${ }^{42}$ Dito isso, do ano fiscal de 1990 ao 1996 , processos ambientais resultatam em sentenças de prisão, totalizando 588 anos. Durante todo tal período, as multas criminais também se elevaram significativamente. No ano fiscal de 1994 , por exemplo, multas totalizando U\$ 36,6 milhöes foram arrecadadas; em 1996, o valor dobrou para $U \$ 76,7$ milhões. ${ }^{4,3}$

\section{Sanções Alternativas}

Apesar da PLETHORA de crimes ambientais e do crescente uso pelos promotores, as sanções criminais são apenas uma pequena peça do quebra-cabeça do cumprimento de disposiçôes ambientais. Existe uma vasta variedade de mecanismos de cumprimento alternativo, os quais se aplicam com muito maior

${ }^{36}$ Pub. L. No. 101-593, § 202 (a), 104 Stat 2954, 2962.

37 Office of Enforcement and Compliance Assurance, U.S. Environmental. Protection Agency, Fy 1996 Enforcement and Compliance Assurance Accomplishments Report 3-43 (Majo de 1997) (daqui para diante ENForCement and COMPLiance RePORT).

39 Office of Enforcement, U.S. Environmental Protection Agency, fy 1991 Enforcement accomplishiments REPORT 3-2 (April 1992).

39 ld.

40 Office of Enforcement ano Complance Assurance, Enforcement and Compliance Report, supramota $36,2-4$.

$41 / d$.

$42 / d$.

${ }^{43} / d$. 
freqüência do que a sanção criminal. A APA pode agir administrativamente para fazer cumprir padrōes da legislação ou de regulação. Ela pode emitir uma ordem administrativa, exigindo que uma entidade monitore ou relate, ${ }^{44}$ para cumprir com exigências regulatórias, ${ }^{45}$ avaliar penalidades, ${ }^{46}$ ou ainda, para tomar medidas remediais. ${ }^{47} \mathrm{~A}$. falha em cumprir com uma ordem administrativa pode levar à imposição de penalidades adicionais. ${ }^{48} \mathrm{~A}$ emissão de uma ordem administrativa de cumprimento ou de uma penalidade administrativa submete-se ao arbítrio da agência, frente a um juiz de direito administrativo. ${ }^{49}$ Pode haver apelação na Corte federal no que concerne a essas penalidades administrativas.

Outrossim, a APA pode buscar o cumprimento de direitos ambientais através de ações civis na Corte. A maioria das leis ambiental confere a APA o poder de solicitar ao Departamento da Justiça para que encaminhe uma Ação Civil em Corte federal em casos de INJUNCTIVE RELIEF/socorro de injunção e penalidades penais. O Departamento da Justiça não irá, ordinariamente, arquivar um caso, a não ser que esteja confiante na sua vitória. Com ereito, muitos réus negociarão um acordo con o govetno, antes do início de uma ação civil. De fato, não é incomum ver uma causa sendo arquivada, simultaneamente com um decreto de proposta de consenso para a aprovaçáo do tribunal..$^{50}$ Esses decretos de acordo freqüentemente impóem penalidades de significância. ${ }^{53}$

Infratores ambientais podem também ser proibidos de contratar e sub-contratar com o governo federal. Uma empresa ou indivíduo pode ser impedido provisoriamente, faltando investigaçöes adicionais ou proibidos de contratar por determinado periodo. Tecnicamente, suspensão e proibição são consideradas meios de protegero governo, não, como meios de punição. ${ }^{52}$ A APA, portanto, é dado poder discricionário para suspender ou proibir uma entidade ou indivíduo de beneficiar-se de indenizações/AWARDS/benefícios de um contrato, empréstimo ou subsídio, se foram acusadas de qualquer violação criminal ambiental. Se um réu é condenado por um crime ambiental, fará parte de uma lista estará obrigatoriamente proibido de contratar com o governo - até o momento em que a causa da condenação esteja corrigida. ${ }^{53}$

Uma revisão do último relatório do Cumprimento e Conformidade revela o grau pelo qual os mecanismos civis de cumprimento dominam sobre sanções

\footnotetext{
${ }^{44}$ E.g., Resource Conservation and Recovery Act, 42 U.S.C. $\$ 6934$ (e).

${ }^{45}$ E.g. Clean Air Act, 42 U.S.C. $\$ 7413$ (a) (1), (3); Clean Water Act, 33 U.S.C. $\$ 1319$ (a).

${ }^{46}$ E.g. Clean Air Act, 33 U.S.C. \$ 1319 (g); Resource Conservation and Recovery Act, 42 U.S.C. $\S 6928(\mathrm{a}),(\mathrm{g})$.

${ }^{47}$ E.g. Comprehensive Environment Response, Compensation, and Liability Act. 42 U.S.C. \& 9606 (a).

${ }^{48}$ Clean Water Act, 33 U.S.C. $\$ 1319$ (d); Comprehensive Environment Response, Compensation, and Liability Act. 42 U.S.C. $\$ 9606$ (b) (1); Resource, Conservation and Recovery Act, 42 U.S.C. $\S 6928$ (a).

49 Clean Air Act, 33 U.S.C. $\$ 7413$ (d).

50 Thomas L. Adams, Enforcement and Liability na p. 44 in ENVIRONMENTAL LAW HANDBOOK (Thomas F.P. Sullivan $14^{\text {a }}$ ed. 1997).

5: Veja, e.g., Office of Enforcement and Compliance Assurance, enforcement and Compliance Report, supra-nota 36, App. B, que contém breve sinopse de cada ação de cumprimento do ano fiscal de 1996.

52 Adams, supramota 49, 44.
} 
criminais, Queixas de penalidades administrativas, ordens de conformidade, citaçōes de campo (FIELD CITATIONS), e encaminhamentos ao Departamento da Justiça totalizaram 2.466 no ano fiscal de 1996 - quase 10 vezes o número de encaminhamentos feitos pela APA para processos criminais. ${ }^{54} \mathrm{O}$ total de penalidades monetárias emitidas em procedimentos civis e administrativos minimiza o que é arrecadado nos procedimentos criminais. No ano fiscal de 1994, as penalidades civis e administrativas ultrapassavam U\$ 120 milhöes; em comparação, as penalidades criminais daquele ano não chegavam a U\$ 40 milhóes. ${ }^{55}$ De forma semelhante, no ano fiscal de 1995, as penalidades civis e administrativas compreendiam mais do triplo do montante das multas criminais. ${ }^{56}$ Os números do ano 1996, contudo, foram muito próximos aos anteriores. Penalidades civis e administrativas foram de aproximadamente U\$ 96 milhóes, comparadas às quase U\$ 77 milhöes em multas criminais. ${ }^{57}$ Até mesmo esses índices subestimam o intervalo entre a arrecadação civil e criminal. Uma vez que o valor monetário da ajuda da injunção/INJUNCTIVE RELIEF obtido esteja concluído, a predominância de sanções civis toma-se ainda mais evidente. ${ }^{58}$

Entretanto, talvez seja mais esclarecedor do que os dados um simples fato. No relatório do ano fiscal de 1996, o Gabinete de Cumprimento e Conformidade dedicou menos de 3 páginas de um total de 88 para a discussão de esforços para o cumprimento criminal. ${ }^{59} \mathrm{O}$ apêndice que resume as açôes de cumprimento em uma base case-by-case destina 75 páginas para as açôes civis e administrativas, e apenas 6 para as criminais. 60

Enfim, por dois motivos, até mesmo essas fontes subestimam a relativa importância do cumprimento civil. Primeiramente, elas incluem apenas açóes federais de cumprimento. $O$ nível de tal atividade é muito maior em várias agências estatais de meio-ambiente. No ano fiscal de 1996, por exemplo, agências estaduais propulsionaram mais de 9.300 ações administrativas. ${ }^{61}$ Em segundo lugar, essas informações também falham em representar as numerosas açóes privadas apreciadas. É difícil sobreestimar o impacto dos processos dos cidadáos/Ação Civil Pública/ CITIZEN SUIT e dos cásos privados de TOXIC TORT/indenização tóxica. A maioria das principais legislaçōes ambientais autoriza os cidadãos em processar

\footnotetext{
${ }^{53}$ Clean Air Act, 33 U.S.C. $\S 1368$ (a); Clean Water Act, 42 U.S.C. $\S 7606$ (a). No que tange à listagem, ver, em geral, Donalo W. Stever \& Eliza Dolin, Eds., Environmental Law \& Practice: COMPLIANCE/LITIGATION/FORMS $§ 22.01$ [6] [a].

54 Office of Enforcement and Complance Assurance, Enforcement and Complanice Report, supra-nota $36,2-2$.

${ }^{55} / d^{\prime} .2-5$.

5s $1 d$.

57 id. A-2.

${ }^{58} / d, \mathrm{~A}-2$.

${ }^{59} / d$.

60 /d. App.B.

${ }^{51} 1 d$. A-6.
} 
no intuito de fazer cumprir leis e regulaçöes e exigências de licenças. ${ }^{62}$ No caso Natural Resources Defence Council v. Texaco Refining \& Marketing, ${ }^{63}$ por exemplo, mais de U\$ 1,5 milhöes em penalidades foi pago como resultado de um processo dos cidadãos/CITIZEN SUIT. Acordos quanto a mudanças de taxas geravam um incentivo para tais tipos de processo. Um tribunal pode atribuir à parte vitoriosa o pagamento das custas do processo incluindo razoáveis honorátios de advogados e de peritos. ${ }^{64}$ Similarmente, a existência de taxas contingente promove uma maior iniciativa na instituição de açôes perdas e danos. Essa modalidade de açóes - comumente referidas como casos de indenização tóxica (TOXICTORT CASES) - são freqüentemente propostas em nome de uma classe ou em nome de grande número de pessoas. O pedido típico dos autores é que as açóes dos réus causaram dano pessoal e/ou patrimonial e podem resultar em consideráveis veredictos. ${ }^{65}$ O medo de um veredicto de uma indenização substancialmente prejudicial, que pode incluir significativas perdas e danos punitivos, também pode significar grande motivação para uma empresa cumprir com os padrões ambientais. ${ }^{66}$

\section{O Papel do Direito Criminal}

O inevitável/FOREGOING revela que o direito criminalé um entre os vátios métodos de cumprimento da conformidade com as leis ambientais. Além disso, é bem provável que seja o método menos utilizado. Isso leva à inexorável pergunta: Considerando-se a vasta variedade de mecanismos civis de cumprimento, incluindo alguns sançöes substanciais, por que um cumprimento racional oficial escolhe buscar as sanções criminais?

\section{A. A obtenção de Sançōes Criminais é mais difícil}

A obtenção de condenação criminal é significativamente mais dificultosa do que a obtenção de julgamento civil. Uma condenação civil requer, por exemplo,

\footnotetext{
${ }_{22}$ Veja, e.g., Clean Air Act, 42 U.S.C. \$ 7604; Clean Water Act, 33 U.S.C. \$ 1365.

${ }^{63} 2$ F. 3 d 493 (3a Cir. 1993).

${ }^{64}$ E.g. Clean Air Act, 42 U.S.C. $\$ 7604$ (d); Clean Water Act, 33 U.S.C. $\$ 1365$ (d).

${ }^{65}$ In Atkins v. Harcross Chem. Co., (La. Distr. Ct. Orteans Parish, No. 89-2396 (Oct. 17, 1996), o rèu, fabricante de pesticidas, alcançou um acordo de U\$51,6 milhões com os 3.800 autores. Para uma envolvente descriç 'ao de um caso de indenização tóxica, Veja Jonathan Harr. A Civil ACTiON (1995).

60ิ Os exemplos de surpreendentes casos de perdas e danos punitivas agora são abundantes. Por exemplo, um júri em Lousiana recentemente avaliou uma indenização por perdas e danos em U\$ 3,4 bilhỏes contra 5 réus, incluindo U\$ 2,5 bithões contra CSX Transportation Inc. 0 acontecimento que precipitou tal indenização produziu extraordinariamente pouco no sentido de dano físico ou patrimonial. Um vagão transportando elementos quimicos incendiou nas proximidades da vizinhança dos autores. A comunidade local teve de evacuar a área, mas o dano patrimonial foi pequeno e as lesões corporais limitarammse a menores problemas como irritação nos olhos e erupções cutâneas. Veja NEW ORLEAns Times-PICAYune, Al (Sept. 9, 1997). A Suprema Corte de Lousiana delxou de lado a indenização. Veja In re New Orleans Train Car Leakage Fire Litigation, 702 So.2d 677 (La. 1977).
} 
um júri que, por unanimidade, considere "fora de qualquer dúvida razoável" que o réu seja culpado pelo que está sendo acusado. Em contraste, os procedimentos judiciais civis impóem muito menor ônus de prova: há preponderância dos depoimentos testemunhais (é maśs provável do que não). Ordens administrativas podem ser emitidas sem qualquer audiência e penalidades administrativas, avaliadas depois de uma audiência administrativa, diante de um juiz de direito administrativo, não, diante de um júri. A revisão judicial dessas penalidades procede sob distintos padrões de revisão. Uma corte de segundo grau irá revogar a determinação administrativa só se não for fundamentada por depoimentos substanciais. Se a decisão for embasada em testemunhos os quais uma mente razoável aceitaria como adequados a fundamentar a decisão, será preservada. ${ }^{67}$ Ademais, um tribunal revisor anular o montante da penalidade imposto apenas se o tribunal considerálo arbitrário e CAPRICIOUS.$^{68}$ Certas proteções constitucionais, a exemplo da Cláusula de Confrontação, são aplicadas apenas em casos criminais. ${ }^{69}$ Descoberta em casos criminal é muito mais limitada.

\section{B. A Sanção Criminal não impede que se recorra a Sançốes Civis}

Uma resposta é que a decisão de lutar por sançóes criminais não impede/ FORECLOSE o uso de sanções alternativas também. Sanções civis e criminais podem ser perseguidas simultaneamente ou sucessivamente. A proteção constitucional fornecida pela Clátisula de Duplo Perigo/DOUBLE JEOPARDY CLAUSE impede apenas que um réu seja processado pelo mesmo crime após ter sido absolvido ou condenado. O réu condenado por uma acusação criminal pode encontrar-se como sujeito passivo em procedimentos civis originários da mesma infração. ${ }^{70}$ De fato, pela da doutrina no collateral stoppel, o réu condenado por uma acusação criminal pode excluir uma nova litigância civil subseqüente no atinente à questão pela qual é responsabilizado." Uma vez tendo o júri considerado "fora de qualquer dúvida razoável" que o réu tenha cometido a violação, o réu estará impedido/ESTOPPED de contestar tal consideração em subseqüentes litigâncias civis. $O$ contrário, todavia, não é verdadeiro. O réu absolvido de uma acusação criminal não estará livre de subseqüentes litigâncias civis. O fato de o júri ter falhado em considerar "fora de qualquer dúvida razoável" que o réu cometeu o crime do qual é acusado não exclui uma investigação fática, vindo a concluir que é mais provável do que improvável que o réu engajou-se na infração. Talvez, surpreendentemente, o fato que o réu foi absolvido por

\footnotetext{
${ }^{67}$ Diamond Ring Rach, Inc. v. Morton, 531 F. 2d 1397 (10 $0^{\text {th }}$ Cir. 1976).

${ }^{68}$ Hudson Stations, inc, v. EPA, 642 F. 2d 261 (8 $8^{\text {lin }} \mathrm{Cir}$. 1981).

${ }^{69}$ U.S. CONST. Amd. VI.

${ }^{70}$ A Double Jeopardy Clause também não protege o réu de ser acusado pela mesma conduta por diferentes ordens autônomas/SOVEREIGNS??? sob a vigência de seus respectivos direitos. Portanto, um ato pode resultar em procedimentos tanto pelo governo federal, sob leis federais, como pelo estado, sob leis estaduais.

71 Veja Bubany, supra-nota $34, \S 12.18$.
} 
uma acusação criminal não irá ordinariamente sequer ser admitido como prova/ testemunho/EVIDENCE em uma ação civil subseqüente. ${ }^{72}$

Evidentemente, se os delitos ambientais forem atacados simultaneamente em diferentes frentes, a multiplicidade de açôes poderá dar lugar a questões processuais complicadas. Se a APA procura uma penalidade civil ao mesmo tempo en que um grupo de interesse ambiental busca uma ajuda de injunçāo/INJUCTIVE RELIEF em um tribunal distrital federal e o Departamento da Justiça está perseguindo um processo criminal, o réu pode buscar uma STAY do processo civil, ${ }^{73}$ Questionamentos podem, também, serem realizados quanto a apelações do privilégio contra auto-incriminação. ${ }^{74}$ (questōes no que toca a auto-incriminação, contudo, pertencem apenas a indivíduos como sujeito passivo na demanda; empresas não se beneficiam do privilégio contra a auto-incriminação). Mas, globalmente, o ponto continua na mesma. A decisão de proceder em um fórum criminal não impede os procedimentos civis, paralelamente. De fato, a vitória no processo criminal pode promover um aumento sensível na probabilidade de vitória no civil, e pode resultar tambén no indiciamento do infrator. ${ }^{25}$

Todavia, isso explica com dificuldades por que um acusado no que concerne ao cumprimento de leis ambientais escolheria empregar uma sanção criminal. Que a sanção criminal não impede a utilização de mecanismos de cumprimentos significa apenas ser possível a imposição de sanções múltiplas sobre um infrator ambiental. Tal seria uma característica desejável, se as sançöes associadas a cada técnica de cumprimento não fossem fortes o suficiente. Seria dificilmente racional criar um sistema de cumprimento no qual existissem métodos de cumprimento, cada um com uma sanção sub-otimizada. Deve-se existir uma variada gama de mecanismos de cumprimento, a sanção associada a cada um deve ser capaz de alcançar o nível desejado de conformidade e intimidação. E há um pequeno motivo para duvidar de que cada uma das ferramentas de cumprimento, no âmbito do meio ambiente, não apresente a necessária força repressiva. As multas civis podem ser substanciais ${ }^{76}$ e indenizações punitivas de perdas e danos são, às vezes, astronômicas. ${ }^{77}$

Muito menos o mero desejo de punir explica a escolha de processar criminalmente. Por tradição, a distinção crucial entre remédios/REMEDIES criminais e civis está entre um remédio destinado a punir o infrator ou, simplesmente, satisfazer/MAKE WHOLE a vítima. A linha de distinção entre ambos apagou-se muito. ${ }^{78}$ Não mais se diz que a linha demarcatória entre as sançóes civis e criminais ficaria na punição culposa. Em inúmeras circunstâncias, remédios civis destinam-se à punição. Multas civis envolvem punição, assim como as indenizaçôes punitivas. Já fica implícito pelo termo que a raison d'être das

\footnotetext{
72 Veja, e.g., Fed. R. Evid., Rule 803 (22) (limitando a exceção de boato de julgamentos anteriores para julgamentos de condenação do crime; julgamentos de absolvição sem excepcionais/ JUDGEMENTS OF ACQUITTALS NOT WITHIN EXCEPTION).

${ }^{73}$ Bubany, supra-nota $34, \S \S 12.12 m 12.14$.

${ }^{74}$ U.S. Const. amd. V.

75 Veja supra-notas 51-52 e texto em anexo.
} 
indenizaçóes punitivas consiste na punição. Elas são adicionadas a quaisquer indenizaçóes quando necessárias para satisfazer/MAKE WHOLE a vítima, no intuito de punir o infrator.

\section{O Desejo de Aprisionamento e de Condenação Moral}

Ultimamente, a decisão de processar criminalmente e não, civilmente, é explicada pelo desejo de invocar as mais duras sanções capazes de ser impostas pela sociedade. Elas incluem restrições à liberdade (estendendo-se desde a perda total da liberdade, isto é, do aprisionamento até restriçōes menores, que podem ser incluídas nos prazos da liberdade condicional) e estigmatização moral/ MORAL ESTIGMA ${ }^{79}$ Nota-se isso em um caso em que uma empresa é ré. A escolha de buscar sançōes criminais contra a empresa acende um desejo de estigmatizar a ré. Uma empresa não pode ser presa. Em termos pecuniários, uma multa civil de U\$ 1 milhão não é menos dispendiosa para uma empresa do que uma multa criminal de U\$ 1 milhão e, dadas as proteções processuais aos réus criminais, são de mais fácil imposição. O desejo de estigmatizar o réu - de publicamente empilhar OPPROBRIUM moral nele - deve, pois, motivar a decisão de desencadear um processo criminal contra uma empresa. ${ }^{80}$ Para indivíduos, a ameaça de prisão combinada com a estigmatização moral produz uma medida adicional de intimidação.

Estigmatização, contudo, exige culpabilidade moral. Em longo prazo, ao menos, o estigma irá apenas aderir àquilo considerado "mau" pela sociedade. Alguém que age infringindo dispositivos criminais não será estigmatizado se sua conduta não for considerada suficientemente repugnante. ${ }^{8 !}$ Simplesmente rotular a conduta de criminal não é suficiente.

Igualmente importante para o senso de culpabilidade moral e estigmatização é o aspecto subjetivo da conduta do réu. De fato, muita doutrina em direito criminal e cásos enfocaram na definição e interpretação da exigência de mens rea. ${ }^{82}$ Isso é expresso substancialmente na velha máxima que THERE IS A BIG DIFFERENCE BETWEEN TRIPPING OVER A DOG E KICKING THE DOG.

Em sua maior parte, houve pouco debate em torno da conduta criminalizada pelos direitos ambientais. De modo geral, o fato de poluir, danificar o meio-

\footnotetext{
76 Veja sinopse de caso in Office of Enforcement and Complance Assurance, Enforcement and Complance Report, supra-nota 36, App. B.

77 Veja supra-nota 65.

${ }^{78}$ Veja, de modo geral, John C. Coffee, Jr", Does "Unlawful" Mean "Criminal"?: Reflections on the Disappearing Tort/Crime Distinction in American Law, 71 B.U.L. Ver. 193, 216 (1991).

${ }^{79}$ Numerosas discussões existern no afinente ao que faz do direlto criminal algo único. Talvez a melhor discussão deste assunto, e no modo com que ele se relaciona aos direitos ambientais pode ser encontrado in Lazarus, Meeting the Demands of integration in the Evolution of Environmental Law: Reforming Environmental Criminal Law, 83 GEORGETOWN L.J. 2407 (1995). Sua discussão influencia bastante o que eu disse no restante deste artigo, embora eu não queira responsabilizá-lo por meus erros ou conclusöes.

$80 / d .2442$.
} 
ambiente, ou de criar condições que põem risco substancial de dano a pessoas ou propriedade é suficientemente HEINOUS de modo a merecer punição criminal não é mais controverso. Considerado o papel crucial da autofiscalização na implementação de direitos ambientais, não há debate significativo sobre a propriedade ou náo do uso do direito criminal como meio de cumprir a conformidade com as exigencias. Sérias perguntas foram levantadas, no entanto, sobre nossa habilidade de articular com precisão suficiente e claridade os tipos de conduta que realmente são qualíficados como poluentes e causadores de riscos substanciais de dano. Conseqüentemente, desafios surgiram para a legitimação do uso do direito criminal no cumprimento de padröes ambientais. ${ }^{83}$

Outra fonte de desafios mais freqüente para a legitimação do direito criminal diz respeito às exigências quanto a aspectos subjetivos do infrator. Muitas das formulações dos crimes ambientais são ambíguas. Elas falham ao definir claramente qual aspecto subjetivo deve associar-se a qual elemento do crime. Os tribunais tenderam a interpretar muitas (mas năo todas) ${ }^{84} \mathrm{e}$ de leis que exigem prova do mínimo aspecto subjetivo. Destarte, os tribunais seguiram um método de análise baseado em duas linhas de casos anteriores à introdução dos crimes ao meioambiente. A primeira linha de casos rotula a doutrina do "agente responsável da empresa". A segunda linha de casos criou a categoria de "delitos ao bem-estar público". O perigo que agora enfrentamos é que se seguirmos mecanicamente essas linhas de casos, ou se a APA e o Departamento da Justiça processarem casos de modo abertamente agressivo, iremos acabar impondo sançōes substanciais criminais e estigmatizando aqueles que não são moralmente culpados. Isso não é sustentável em longo prazo. O desrespeito ao direito irá aumentar; a habilidade de implementar o direito será minada; e sua capacidade de servir como força educativa irá erodir.

\section{A Doutrina do "Agente Responsável da Empresa" (Responsible Corporate Officer Doctrine)}

\footnotetext{
${ }_{81}$ Um exemplo recente pode ser encontrado na reação do público americano a alegações do Presidente Clinton em um julgamento, ao negar ter tido relaçöes sexuais com Monica Lewinsky. Fol amplamente noticiado que a reação comum às suas alegações era que mentir sobre um caso amoroso poderia ser compreensivel. Muitos disseram que teriam feito o mesmo se na situação do Presidente. Talvez esta seja a razão do aumento na taxa de aprovação de Clinton na época em que foj acusado de perjúrio. O perjưtio infringiu dispositivos legais, ainda que não fosse suficiente para ocasionar OPPROBRIUM moral. 82 Veja, de forma ampla, MODEL PeNal COOE $\S 2.02$ (define aspectos subjetivos como intençäo, imperícia, imprudéncia e negligência)

s Veja, Parte IV.G infra.

${ }^{84}$ Os crimes conscientes de perigo são exceção. Eles requerem claramente que o réu saiba do risco criado por sua conduta. Veja, e.g., Clear Water Act, 33 U.S.C. § 1319 (c) (3) (A) ("saiba ao tempo que ele coloca uma pessoa em perigo iminente de morte e séria lesăo corporal"); § 1319 (c) (3) (B) (i) (ao determinar se a pessoa sabia que sua conduta colocava oura em iminente perigo "a pessoa é responsável apenas por real consciência ou opinião real que tinha"; conhecimento detido por outra pessoa não pode ser atribuído ao réu).
} 
Empresas estão entre as "pessoas" que estão sujeitas à responsabilização criminal sob direitos ambientais. ${ }^{85}$ De modo geral, uma empresa pode ser responsabilizada por uma infração de um empregado ou agente quando eles agitam no âmbito de seu emprego ou agência e para o benefício da empresa. ${ }^{86}$ Empresas, obviamente, não podem ser presas. Agentes da empresa, entretanto, podem estar sujeitos a sanções criminais (e prisão) através da aplicação da doutrina do "agente responsável da empresa".

Os contornos da doutrina do "agente responsável da empresa" são vivamente destacados por uma revisão da decisão da Corte Suprema de 1985 em United States v. Park. ${ }^{87}$ Os fatos do caso são bastante simples. Park era chefe executivo na Acme Markets, Inc., uma cadeia nacional varejista de alimentos, com aproximadamente 36.000 empregados, 876 postos de venda, 12 depósitos gerais e 4 depósitos especiais. Em 1971, a Food and Drug Administration (FDA) advertiu a Park, por carta, de uma inspeção em um dos depósitos da empresa que revelou infestação de roedores e outras inconformidades sanitárias. Uma segunda inspeção, feita alguns meses após, demonstrou melhoras nas condições sanitárias, embora continuasse o problema dos ratos. Acme Markets e Sr. Park foram, então, acusados por violação do Food, Drug and Cosmetic Act, por deixarem os depósitos expostos à contaminaçăo. Acme advogou culpa em todos as cinco contas da indiciaçăo, mas o Sr. Park contestou as acusaçôes.

No seu julgamento, Park depôs que quando do recebimento da carta da FDA, alertando-o das condições sanitárias, ele conversou com o Vice-presidente da Acme de assuntos jurídicos, que disse que uma divisão da vice-presidência da Acme estava investigando a situação e que tomaria as medidas corretivas necessárias. Embora Park reconheceu que como chefe executivo ele era "responsável por toda a operação da companhia", ele testemunhou que essa era uma das tarefas delegadas a ele na empresa. $O$ tribunal instruiu o júri de que Park poderia ser condenado mesmo que se não tivesse atuado conscientemente ou que se tivesse pessoalmente participado da situação. Tudo o que o governo tinha que provar era que Park, em virtude de sua posição na empresa, tinha autoridade e responsabilidade pela questão. O júri condenou Park, o que foi confirmado pela Suprema Corte.

Assim sendo, o Tribunal defendeu a proposição, anunciada 30 anos antes de United States v. Dotterweich, ${ }^{88}$ que a partir do Food, Drig and Cosmetic Act, um agente da empresa pode ser considerado criminalmente responsável pela conduta de outros agentes, baseando-se apenas na prova de que ele podia ter agido no sentido de remediar o problema. O ônus colocado sobre aquele agente era, talvez, "além da demanda e talvez oneroso", escreveu o Tribunal, mas "não menos

\footnotetext{
${ }_{85}$ Veja, e.g., Clean Water Act, 33 U.S.C. $\$ 1319$ (c), 1362 (5); Safe Drinking Water Act, 42 U.S.C. $\S 300 f ;$ Resource Conservation and Recovery Act, 42 U.S.C. $\$ 6903$ (15); Clean Air Act, 42 U.S.C. $\S 7413$ (c) (6); 7602 (e).

86 Sobre responsabilização da empresa, de forma geral, Veja WaLter R. LAFave, Criminal Law $\S$ $3.10(1986)$.

87 421 U.S. 658 (1975).
} 
rigoroso do que o público ter o direito de esperar daqueles que voluntariamente assumem posições de autoridade em empresas cujos serviços e produtos afetam a saúde e bem-estar do público que as sustenta" ${ }^{39}$ Embora essa decisão tenha ocasionado algumas dissidências, ${ }^{30}$ a doutrina do "agente responsável da empresa" é uma parte já estabelecida da paisagem do direito ambiental.". Tanto o Clean Water Act, como o Clean Air Act explicitamente incluem "qualquer agente responsável da empresa" na definição de "pessoa" a qual se aplicam as disposiçōes criminais. ${ }^{92}$ Mas a extensão pela qual Park e Dotterweich afirmam a responsabilização criminal de agentes da empresa por violaçōes ao meio-ambiente cometidas pelos seus subordinados não foi ainda solucionada. Resta ainda alguma confusăo nos tribunais, em grande parte devido à persistenre confusão sobre a natureza das exigências de aspectos subjetivos demandados nos "delitos ao bem-estar público".

\section{E. Delitos ao Bem-Estar Público}

O conceito de "delitos ao bem-estar público" tem suas origens nos primórdios deste século. Como explicou a Suprema Corte no leading case United States v. Morissette, ${ }^{93}$ o termo havia sido cunhado para descrever uma nova classe de legislação, que buscaria responsabilizar os infratores sem requerer a demonstração da mens rea. Delitos ao bem-estar público não se parecem com crimes tradicionais do common-law. Melhor do que criminalizar "agressões e invasóes positivas", eles impunham responsabilização por "negfigência onde a lei exige cuidado, ou inação onde a lei impöe dever"..$^{94}$ Delitos ao bem-estar público utilizavam-se do direito criminal para aumentar o cumprimento de regimes regulatórios, cujo foco estava na conduta criadora do perigo ou da probabilidade de perigo para a sociedade em geral. Diluir ou, mesmo, eliminar a tradicional exigencia de mens rea era aceitável por duas razöes principais. Primeiro, réus ptocessados por delitos ao bem-estar público estavam, usuralmente, numa posição capaz de prevenir o dano temido, mediante o exercício da diligência devida. Ademais, delitos ao bem-estar público tipicamente ensejavam apenas penalidades leves, sendo que a condenação em razão deles "não lesionava seriamente a reputação do infrator". 95

O Food, Drug and Cosmetic Act relacionado a Park e Dotterweich consistiu num clássico exemplo de delito ao bem-estar público. Em seus termos, o Act impunha responsabilidade criminal sem necessidade de demonstração de uma situação subjetiva do infrator culpável. O Tribunal não queria inferir que essa omissão

\footnotetext{
320 U.S. $277(1943)$.

89421 U.S. 672.

${ }^{90}$ Veja, e.g. Edward F. Novak e Charles W, Steese, Survey of Federal and State Environmental Crime Legislation, 34 ARZ. L. VER. 571,576 N. 44 (1992).

"Majs sobre a doutrina do "agente responsdvel da empresa", Veja Cynthia $\mathrm{H}$. Finn, The Responsible Corporate Officer, Cniminal Liability, and Mens Rea: Limitations on the RCO Doctine, 46 AM. U. L. VER. 543 (1996).

${ }^{9}$ Clean Water Act, 33 U.S.C. $\S 1319$ (c) (6); Clean Air Act, 42 U.S.C. $\$ 7413$ (c) (6).

342 U.S. 246 (1952).
} 
foi sem querer; recusava-se a significar qualquer situação subjetiva do agente. Como ocorre com muitos crimes regulatórios, todavia, a aplicação da doutrina do bem-estar público a crimes contra o meio ambiente é muito mais problemática. A maior parte das leis criminais - mesmo aquelas que fazem parte de arranjos regulatórios - inclui alguma exigência quanto ao aspecto subjetivo do agente. $O$ típico caso do delito ao bem-estar público faz com que um tribunal aplique a teoria no intuito de resolver quanto ao significado da exigência de culpabilidade. A Seção 309 do Clean Water Act, por exemplo, estende a responsabilidade criminal a qualquer pessoa que conscientemente viola quaisquer seções listadas no Act. ${ }^{96}$ Uma destas outras seções, a 301, proß̉be a adição de poluentes a águas navegáveis, a partir de uma fonte natural..$^{97}$ Então, se um réu é acusado de violar conscientemente a Seção 301 , o quê, precisamente, precisa ser provado para obter a condenação? Deverá ser provado que o réu sabia que sua conduta violava o direito?; Que ele sabia o que estava adicionando, que ele sabia ser um poluente, ao que sabia ser águas navegáveis, de onde ele sabia ser um "lugarfonte", mas que ele não sabia que isso era ilegal?; Que ele sabia o que fazia, mesmo que ele năo soubesse se se tratava de poluente ou, de águas navegáveis, ou de "lugar-fonte?"; ou de alguma combinação deles?

Responder a isso, ou a questōes similares, significa uma tarefa difícil para os tribunais. Isso se deve parcialmente à ambigüidade inerente às leis pouco articuladas/ esboçadas/DRAFTED. Também se deve parcialmente a uma confusão analítica. A confusão analítica é evidenciada até mesmo no vocabulário da jurisprudência. Os tribunais comentam freqüentemente, no tocante aos delitos ao bem-estar público, quanto à imposição de "responsabilidade estrita" aos réus. Dessa forma, contudo, deixaram imprecisão em significarem ou não que o réu possa ser condenado sem a demonstração de uma situação subjetiva, que a lei exija menores aspectos subjetivos do que o tradicionalmente exigido, ou que tais condições subjetivas do réu foram eliminadas do rol de elementos do crime. ${ }^{98}$ Uma breve revisão de dois casos chaves da Suprema Corte ilustram a confusão que atormenta a área.

O caso United States v. International Minerals \& Chemical Corp. ${ }^{99}$ envolveu uma formulação legal bastante assemelhada ao Clean Water Act e a outras leis ambientais. Neste caso, o réu foi acusado com base em uma lei que tipificou como crime a "violação consciente" de dispositivos da Interstate Commerce Commission, que regula o transporte de líquidos corrosivos. Os dispositivos em questão exigiam daqueles que transportam material perigoso a descrição de sua natureza nos próprios documentos de transporte. ${ }^{100} \mathrm{O}$ réu alegou que a indiciação - que falava da ausência de documentos de transporte nos quais constasse a indicação do transporte de liquido corrosivo - não tinha argumentado sobre a consciência por parte do autor na violação do dispositivo. O réu assertou que náo

\footnotetext{
94/d. 255.

95 Id. 256.

${ }_{96} 33$ U.S.C. § 1319 (c) (2) (A).
} 
podia ser condenado por violação consciente de dispositivos, a não ser que o govemo provasse que ele conhecia o conteúdo desses dispositivos legais.

A Suprema Corte rejeitou tal argumento. Ao elaborar o documento e redigir "conscientemente violar tal regulação", o Congresso objetivou que a palavra "regulação" significasse "designação em curto prazo para específicas açōes ou omissóes que violem o Act". ${ }^{101}$ Em outras palavras, o réu deveria saber o que estava fazendo: que estava realizando o transporte marítimo de líquido corrosivo sem os documentos respectivos no que toca à sua natureza. Conhecimento da legislação não é necessário. Ainda que o réu acredite - erroneamente - transportar água destilada não possa ser condenado, a prova de que estava transportando ácido sulfúrico basta. A lei não exige que seja provado que o réu sabia da regulamentação ao transporte marítimo/FLUVIAL/DE NAVEGAÇÃO ou da exigência de documentos apropriados para o transporte do material. A Corte fundamentou sua decisão de exclusão da prova de qualquer aspecto subjetivo no que conceme à regulação, em termos tais que são empregados em outros casos de meio-ambiente.

"onde (...) perigosos e DELETERIOUS aparelhos ou produtos ou detritos estão envolvidos, a probabilidade de regulamentação é tão grande que qualquer um que esteja consciente da posse deles ou lidando com eles presumem-se conhecedores da legislação."

Mais recentemente, o Corte abordou uma provisão do National Firearms Act no caso Staples v. United States. ${ }^{102}$ Essa lei toma ilegal a posse de uma arma de fogo sem registro. ${ }^{103}$ Dentre as características que fazem de uma arma uma "arma de fogo" é sua capacidade de disparar automaticamente. ${ }^{104}$ O réu não contestou o fato de possuir uma arma de fogo ou de ela não estar registrada. Ele argüiu, todavia, que ele näo poderia ser condenado pela lei por não saber que sua anna era capaz de disparar automaticamente. Isto é, ele sustentou que a lei exigia a prova de que ele estava consciente das características que conduziam à definição de "arma de fogo". Apesar da falta de qualquer aspecto subjetivo legal expresso, a Suprema Corte concordou. Ressaltando a importância da mens rea no direito criminal, a Corte afirmou que "delitos que não exigem mens rea são, comumente, desfavorecidos", e que "uma indicação de intenção legislativa, expressa ou tácita é necessária para que se prescinda da mens rea como elemento do crime". ${ }^{105} \mathrm{Em}$ uma parcela confusa da decisão da Corte buscou distinguir o National Firearms Act de outras leis - tratando de delitos ao bem-estar público, interpretando-os como crimes que (1) prescindem das convencionais exigências da mens rea, (2) acabaram com a imposição

\footnotetext{
${ }_{97} 33$ U.S.C. $\$ 1311$ (a).

99 Veja Staples v. United States, 511 U.S. 600, 600-07 n.3 (1994).

${ }_{99} 402$ U.S. $558(1971)$.

10049 C.F.R. $\$ 173.427$.

10: 402 U.S. 562.
} 
de forma rigorosa da responsabilidade estrita/STRICT LIABLLITY e (3) eliminaram qualquer exigência da mens rea. ${ }^{106}$ A tentativa de diferenciar o National Firearms Act de outros delitos ao bem-estar público é curiosa, sendo que a decisăo da Corte em Staples foi exatamente o que decidiu no Intemational Minerals e outros casos. Ela interpretou a lei cono exigindo conhecimento dos fatos (de que a arma possuía as características compreendidas pela arma de fogo), mas não da lei (da necessidade de registro). ${ }^{107}$ Quando a linguagem ambígua do direito ambiental é considerada junto com essa discussão pouco lúcida sobre delitos ao bem-estar público, pode-se dificilmente admirar-se com a dificuldade enfrentada pelas instâncias inferiores na interpretação de leis ambientais.

\section{F. Interpretação de Leis Ambientais}

Mais uma vez, uma pesquisa minuciosa sobre o modo com que os tribunais têm interpretado as variadas provisões ambientais criminais está além do objetivo deste artigo. ${ }^{105}$ Uma amostra desses casos notáveis deve, entretanto, ser suficiente para entender a confusão e detectar algumas tendências. Os tribunais, ao interpretarem a RCRA, por exemplo, concordam em algumas questões e discordam em outras. Sob a RCRA, um indivíduo comete delito quando, conscientemente, trata, armazena ou dispõe de materiais perigosos sem licença. ${ }^{109}$ Os tribunais concordam que no processo a partir da RCRA, o governo não precisa provar que o réu sabia da ilegalidade de sua conduta ${ }^{10}$ Deste jeito, eles concordaram que a acusação/PROSECUTION deve provar que o réu sabia que estava tratando, estocando ou dispondo de materiais/ WASTE ${ }^{11}$ perigosos ${ }^{112}$. Mas eles discordam quanto à exigência de prova no atinente ao desconhecimento da existência da licença. ${ }^{113}$

O Clear Water Act declara ilegais as violações conscientes de suas várias seções enumeradas. Baseando-se nos International Minerals, os tribunais foram bastante consistentes em afirmar que a acusação tinha apenas que provar que o réu sabia da natureza de sua conduta e que um poluente estivesse envolvido. ${ }^{114}$ Ainda aqui, a análise dos tribunais e juristas é freqüentemente confusa. Por exemplo, um dos maiores tratados de direito ambiental descreve a recente decisão do $5^{\text {th }}$ Circuit no caso United States v. Ahmad ${ }^{155}$, tanto estabelecendo a exigência de conhecimento no Clean Water Act aplicada a cada elemento do delito como também rejeitando o

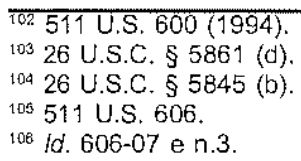

107 De fato, a Corte aparentemente não iria exigir prova de que o réu tivesse consciência de todos os fatos relevantes. Parece não ser necessário provar que o réu sabia que a arma não estava registrada. Cf. United States v. Freed, 401 U.S. 601 (1971) (no National Firearms Act, devemse provar que o réu sabjia que tinha posse de uma granada, mas não que a granada não era registrada).

tce Para uma discussão mais completa, deve-se recorer a levantamento anual sobre white-collar crime feito pela American Criminal Law Review, que indul um artigo recente sobre crimes ao meio-ambiente. Veja, eg., Envionmental Crimes, 34 Amer. Crim. L. Ver. 491 (1997). Veja tarnbém Stanley A. Twardy, Jr. e Michael G. Considine, Mrat Must One "Know" to Be Convicted Under the Environmental Laws, 11 NaT. REs. \& EN. 48 (SFFalNG 1997); Longona, supranota 4. 
Clean Water Act como modalidade de um delito contra o bem-estar público. ${ }^{116} \mathrm{O}$ afirmado no caso Ahmad não vai muito longe disso. Apenas sustenta que ao govemo cabe provar que os réus sabiam que estavam despejando gasolina, um poluente, e não, água. Não estabeleceu que a acusaçăo deveria provar que os réus sabiam que estavam despejando gasolina de um lugarfonte/POINT SOURCE, outro elemento que consta na lei. Além disso, enquanto o tratado esteja correto ao relatar que o tribunal responsável pelo caso Ahmad justificou sua interpretação da lei, rejeitando a noção de que o Clean Water Act envolve delito ao bemestar público, o tratado falha ao constatar que no caso United States v. Weitzenhoff ${ }^{17} \circ 9^{\text {th }}$ Circuit da Corte de Apelação justificou exatamente a mesma interpretação da lei, argüindo que o Clean Water Act era um delito ao bem-estar público. ${ }^{1: 8} \mathrm{O}$ conceito de delito ao bem-estar público é, de fato, esquivo.

\section{G. Uma Crítica}

Um problema mais crítico em potencial do que a confusão analítica encontrada em casos é a idéia da aplicação de padróes reduzidos da mens rea aos crimes ambientais. O Professor Richard Lazarus tem sido um crítico dessa tendência. Mesmo com o risco de simplificar demais suas idéias, tentarei resumir sua argumentação. "19 Ele sustenta que os direitos ambientais possuem certas características que os tornam inapropriados na criminalização de violaçōes a partir de exigencias reduzidas de aspectos subjetivos. Tais características incluem aspirações do direito ambiental - o fato de que as leis ambientais não objetivam codificar as já existentes normas de conduta, mas promover dramáticas mudanças na maneira como as pessoas e empresas se comportavam. ${ }^{120}$ Padrões são comumente dispostos em níveis irreais; conformidade nem sempre é executável. ${ }^{121}$ Em segundo lugar, Lazarus aponta para a característica dinâmica do direito ambiental. Em

\footnotetext{
${ }_{109}^{109} 42$ U.S.C. $\$ 6928$ (d) (2) (A).

110 Veja, e.g., United States v. Laugh|in, $10 \mathrm{~F}$. 3d 961, 965-66 (2 ${ }^{\text {nd }}$ Cir. 1993); United States v. Self,

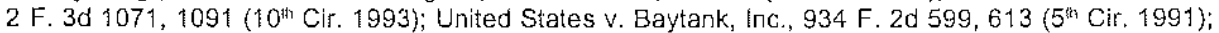
United States v. Hoflin, 880 F. 2d 1033, 1037 (9 Cir. 1989), cert. Negado, 493 U.S. 1093 (1990); United States v. Johnson \& Towers, Inc., 741 F. 3d 662, 669 (3: Cir. 1984).

1 Veja casos citados na nota 109 , supra.

112 O réu não precisa saber que a substância é definida como detrito perigoso; apenas da danosidade (capacidade de causar dano) da substância.

${ }^{113}$ Comparar com, e.g., United States v. Baytank, Inc., $934 \mathrm{~F} \mathrm{2d} \mathrm{599,613}$ (5 $5^{\text {th }}$ Cir. 1991), e United States v. Johnson \& Towers, Inc., $741 \mathrm{~F} 2 \mathrm{~d} \mathrm{662,669}$ (3 $\mathrm{Cir}$. 1984) (exigindo o conhecimento da falta de ficença) com United States v. Wagner, $29 \mathrm{~F}$. 3d 264 ( $7^{\text {th }}$ Cir. 1995), United States v. Laughlin, 10 f. 3d 961, 965-66 ( $2^{\text {nd }} \mathrm{Cir}$. 1993), e United States v. Hoflin, 880 F. 2d 1033, 1037 (9 th $^{\text {Cir. }} 1989$ ), cer. denied, 493 U.S. 1093 (1990) (prova do conhecimento da falta de licença dispensada).

${ }^{114}$ Veja, e.g., United States v. Ahmad, 101 F.3d 386, 389-91 (5 ${ }^{\text {th }}$ Cir. 1996); United States v. Hopkins, 53 F. 3d 533, 537-41 (2 ${ }^{\text {nd }}$ Cir. 1995), cert. denled, 516 U.S. 1072 (1996); United States v. Weitzenhoff, 351275,1284 ( $9^{\text {th }}$ Cir. 1993), cert. denied, 513 U.S. 1128 (1995).

$115101 \mathrm{~F} .3 \mathrm{~d} 386\left(5^{\text {th }} \mathrm{Cir} .1996\right)$.

$\$ 18$ Bubany, notamsupra 34 § 12.38 (Supp. 1997).

11735 F. 3d 1275, 1284$) 9^{\text {in }}$ Cir. 1993), cert. denied, 513 U.S. 1128 (1995).
} 
virtude de estarem profundamente enraizados na ciência e tecnologia, os padrões estão em constante modificação. ${ }^{122}$ Em terceiro lugar, a complexidade dos direitos ambientais separa-os do regime típico do direito criminal. Eles são extremamente técnicos, muitas vezes indeterminados (por exemplo, é sempre difícil determinar se algo é nascente ou corpo d'água, tais como terrenos alagadiços, qualificáveis como "trechos navegáveis"), e difíceis de localizar entre a gama de leis, regulamentos, preâmbulos, diretivas e cartas. ${ }^{123}$

Dadas essas características do direito ambiental, é fácil contatar como alguém pode violar um padrão ambiental sem culpabilidade moral. E, diferentes dos clássicos delitos ao bem-estar público, os crimes ambientais agora trazem consigo penalidades substanciais. No caso United States v. Park, o réu foi multado em U\$ 50 por cada uma das 5 COUNTS. ${ }^{224}$ En contraste, muitos crimes ambientais são agora FELONIES/crimes/contravençōes, com potencialidade para penas longas de prisão e multas pesadas. Outrossim, distinta dos clássicos delitos ao bem-estar, a condenação por delitos ao meio-ambiente foi destinada a causar "sétios danos à reputação do infrator". ${ }^{125}$ Aqueles que buscam o cumprimento dos direitos ambientais, agressivamente, através de mecanismos criminais de cumprimento, em vez de civis, correm o risco de prejudicar o valor originário da criminalização de infrações ambientais, expressando a desaprovação da moral social.

\section{H. Os Acusadores devem ser Prudentes}

Portanto, tendo-se em vista a atual condição do direito, o exercício prudente do arbítrio da acusação consistirá na chave para uma aproximação justa ao cumprimento ambiental. Tanto a APA como o Departamento da Justiça estabeleceram diretivas/WRITTEN POLICIES no sentido de guiar tal arbítrio. As orientações da APA estabelecem princípios que regem o início da investigação criminal. Tais orientações significam o OVERARCHING princípio que a "autoridade de cumprimento criminal deveria enfocar os violadores mais significativos e egrégios". 126 Dois fatores devem ser seguidos - a medida do dano significativo e o nível de culpabilidade.

Levando-se em conta a correspondência ao dano significativo ao meioambiente, as orientaçóes da APA identificam 4 sub-fatores: (1) dano real, que promova identificável ou impacto danoso significativo para a saúde humana e meio-ambiente; (2) ameaça de dano significativo, devido a uma real ou ameaça de

\footnotetext{
$115 / d .1286$.

${ }^{119}$ A versäo completa de sua argumentaçăo pode ser encontrada em Lazarus, notamsupra 78. 120 /d. 2424-26.

$12:$ Lazarus cita uma pesquisa sobre agentes de empresas em que $2 / 3$ conheciam infrações a padrões ambientais de um ano interior. Id. 2425 n.73.

122 Id. 2426-28.

$123 / d .2428-38$.

124421 U.S. $658,686(1975)$.

125421 U.S. $658,666(1975)$.
} 
descarga, despejamento ou emissão; (3) falha ao relatar real descarga, despejo ou emissăo, na ocorrência dos dois primeiros sub-fatores; e (4) se uma conduta ilegal parece representar una tendência ou atitude usual em meio à comunidade, de sorte que uma investigação criminal produziria un efeito intimidador.

O segundo fator concentra-se na culpabilidade do infrator. A conduta culposa é passivel de identificação através de: (1) uma história de violaçōes repetitivas; (2) infração deliberada, resultando em violação; (3) ocultação da infraçăo ou falsificação de registros requisitados; (4) manutenção de equipamento de controle ou monitoramento; (5) atividades relacionadas sem autorização, licença, etc. ${ }^{127}$ Empresas são provavelmente mais investigadas quando passaram por auditoria ambiental e conscientemente falharam em remediar prontamente a desconformidade ou corrigir o dano causado. Uma vez que a APA envie um caso ao Departamento da Justiça para processo criminal, ocorrerá uma revisão similar. ${ }^{128}$

Ultimamente, contudo, a justiça e sucesso dos sistemas relacionam-se no julgamento medido daqueles acusados quanto ao cumprimento. Infelizmente, nem todas decisões sobre o procedimento são feitas em uma atmosfera calma e razoável. A maioria de ocorrências ambientais, tais como o derramamento de óleo ExxonValdez, ensejam alta divulgação na mídia. Pressão política irá propiciar o processo criminal dos poluidores, ainda que em alguns casos uma visão desapaixonada dos fatos podería levar à conclusão de que o procedimento criminal é UNWARRANTED/não é garantido/sem mandado de prisão, busca/. Por outro lado, há exemplos em que a pressão política leva ao outro caminho processual. ${ }^{129}$ $O$ processo criminal pode ser garantido/WARRANTED, mas o alvo pode exercer influência política substancial. Estes não são temores hipotéticos. Os esforços da APA no tocante ao cumprimento de padrões ambientais já estiveram sujeitos a consideráveis críticas e revisão significativa. ${ }^{30}$

\section{Conclusão}

A disponibilidade das sanções de direito criminal fornecen aos autores que almejam o cumprimento de padrões ambientais uma arma importante. Poluidores que previamente intentam internalizar o custo das sançöes e repassa-los aos consumidores agora terāo de considerar que as infraçōes ambientais resultarão em prisão: um custo que há de ser relevado. O poder do abuso de direito também está inserido no poder de fazer cumprir. A vagueza com que muitas leis são redigidas, as características especiais dos direitos ambientais, e a alta politização da natureza das batalhas ambientais fazem da possibilidade de abuso algo real. A sub-utilização $\overline{126}^{126}$ United States Environmental Protection Agency, The Exercise of investigation Discretion 1 (June $12,1994)$.

$127 / d$.

128 Veja United States Department of Justice, Uniteo States Defartment of Justice Manual. Factors in Degisions on Criminal Prosecutions for Environmental Violations in the Context of Significant Voluntary Compliance or Disclosure EFForts By The Violator (July 1, 1991), 
dos direitos ambientais irá, indubitavelmente, contribuir para um senso geral de cinismo em relação ao governo - o que já existe. A supra-utilização, todavia, coloca uma ameaça distinta. Em curto prazo, as penalidades serão impostas a quem não as merece. Em longo prazo, a supra-utilização irá minar os direitos ambientais. Irá despi-los de sua força moral, sua razão de ser. Enfim, o "fazer cumprir" sempre será algo bastante delicado.

\footnotetext{
¿29 Mesmo que tanto a Exxon Corp. como o capităo do Valdez tenham sido processados, alguns criticaram a falha do governo em processar os funcionários de alto nivel da Exxon e a Alyeska. Pipeline Company.

${ }_{130}$ Veja Programa de Cumprimento Criminal da APA, Hearing before the Subcomm. On Oversight and Investigations of the House Comm. On Energy and Commerce, 102 ${ }^{\text {nd }}$ Cong., $2^{\text {nus }}$ Sess. (1992); Jonathan Turley, Criminal. Environmental Prosecution by The Uniteo States Department of Justice PRELIMINARY REPORT (1992).
} 